\title{
Safety and Labor Health, Corporate Social Responsibility with Return of Economic Benefits
}

\author{
Jesus Ernesto Rocha-Ibarra, PhD \\ Yashiro. Danahi Cisneros-Reyes, MA
}

University of Guanajuato, Mexico

Doi: 10.19044/esj.2018.v14n13p37 URL:http://dx.doi.org/10.19044/esj.2018.v14n13p37

\begin{abstract}
This article is a quantitative and qualitative case study of the SelfManagement Program Occupational Safety and Health (P.A.S.S.T.) implemented in twenty-five Mexican companies. The analysis is based on the theories of business ethics, corporate governance and the concept of publicprivate partnerships to explain the achieved link by the Ministry of Labor and Social Prevision (S.T.P.S) and the Private Initiative to improve the safety conditions and health within the companies. After reviewing the results of the data obtained by the companies, it was found that there are financial benefits and quality in processes, derived from the good corporate governance.
\end{abstract}

Keywords: Corporate Social Responsibility, Safety and Labor Health

\section{Introduction}

The economic and social development of a country can be explained considering different perspectives and stakeholders; the State and the company is a binomial linked to this purpose, both are combined to delimit the functions, and the economic - social market scope.

The importance of the decisions and the actions derived from this public-private relationship is high because it has direct consequences on the population, the roles of the persons (worker, consumer, entrepreneur, politician, etc.). Therefore, each plan, program or law must be considered from the basic principle of improvement of the life quality of any human being. Sen, A. (2000). The use of markets development is important because it is the unique role for social support, public regulation and policy as the mentioned above can enrich rather than impoverish the human life.

When referring to wealth and poverty is not exclusively in financial terms, as a person can be enriched in areas of health, culture, recreation or others; in practical terms increasing the living conditions. 
The proposed question explore whether or not the implementation of a safety and health program in a work area was effective, as well as to inquire about the benefits obtained. Finally, it is established that the Corporate Social Responsibility can be considered as an investment with returns.

The main idea, empirically accepted in Mexico, is that the Corporate Social Responsibility C.S.R. is restricted to the company that gives some benefit to the society, regularly in a local area as a philanthropy act. This article discuss another aspect related to C.S.R. additional to the well-known elements of social welfare, sports support or ecological sustainability; those eventually give the company a better image to face their consumers, competitors, government agencies and other stakeholders.

The proposed idea might be more precarious but not less interesting as we are predicting the social and economic development, from the consideration of the company towards its own workers. The improvement in the conditions of the work area can lead to the improvement of the conditions of the society in general as the worker is the supporter of the basic needs (food, clothing, education and recreation) for his/her family; it must be considered that the family remains as the principal component of the society.

Additionally, the company also receives benefits derived from the implementation of the C.S.R. For example, it has been proved that a worker who has good working conditions and environment is more productive; as he/she has perception that his/her family is being well provided then it is easier to focus just on the labor without any familiar concerns. Then, the family plays an important role because by observing the high standards of work quality that the company offers to the worker (father, mother or other) a feeling of identification and recognition of the benefits appears.

The presented tripartite concept, in which we already involved the company, the worker and his family, is complemented by the State that creates policies. For this case, State is represented by the Secretary of Work and Social Welfare (S.T.P.S.) that created a program of self-management in occupational safety and health as an attempt to make the company responsible in a win-win relationship, on the one hand concerned about the welfare of the workers but on the other, to the derived productivity and economic benefits.

\section{Corporate Social Responsibility}

C.S.R. is a broad term, which, in a generic way, is the universe of economic, environmental and social interventions carried out by the companies in favor of the social welfare. The impacts of these interventions, as well as the scope and limitations, are at the core of an integrative vision that includes those who belong to the business sector, the government sector and civil society, as the main stakeholders. 
According to the Mexican Center for Philanthropy Cemefi, the Corporate Social Responsibility is a conscious and consistent commitment to comply fully both the internal and external objectives of the company, taking into account the economic, social and environmental expectations of all its participants, respecting people, values, ethics, community and environment, thus contributing with the construction of the common welfare.

The Mexican standard NMX-SAST-26000-IMNC-2011 defines the C.S.R. as the organization responsibility of the impacts that its decisions and activities cause for the society and for the environment, through a transparent and ethical behavior that contributes to the sustainable development, including the health and the society welfare; taking into account its stakeholders expectations; fulfillment of the applicable local legislation, international behavior standards consistency and finally integration and implementation of the organizational relations.

ISO 26000 defines the Social Responsibility as follows: "the responsibility of an organization for the impacts that its decisions and activities cause to the society and the environment, through ethical and transparent behavior that contributes to sustainable development, including the health and the society welfare, taking into account the stakeholders expectations, the law , international behavior standards consistency, and finally the integration and implementation of the organizational relations."

Although C.S.R. is a concept still explored and improved; for example, Rochlin (2005) writes that it is common that C.S.R. gets confused with acts of goodwill such the construction of building schools in the places where the companies are located or even with philanthropy, as a donation to cultural or artistic foundations. Certainly the debate is broad, it is even difficult for authors and organizations to issue a complete definition of the C.S.R. but despite this, the social dynamics is responsible for the feedback.

However, we can find common elements such as those mentioned by Vargas, M. (2009): a. compliance with legal regulations as the basis of the C.S.R.; b. the relevant role of the contribution to the improvement of the people life quality and the environment; $c$. the voluntary nature of corporate actions; d. the definition of ethical values and transparency; e. the social demand: stakeholders and society increasingly demand ethical and legal behavior; f. a strong reputation as an essential element that ensures the trust; g. the verification through the evaluation and elaboration of their reports from the triple rendering of accounts (environmental, financial and social), and $h$. the public policy to strength the Social Responsibility.

Thus, the C.S.R. is clearly far away to be considered just as a philanthropic concept. In any case, it covers the whole operational structure of the company, not only the image that tries to represent but also the carried out practices. It is also clear that it is not the individual effort the component that 
makes a successful C.S.R. project, it is required the involvement of the members of the whole value chain of the company. The results of these practices will potentially have a shared impact according to the political economy, the markets, the State and the society as a total entity.

\section{Business Ethics Perspective}

From the perspective of the business ethics, we can discuss whether the company has or not an obligation different from the production of goods and services that satisfy the society needs, within the legal framework imposed by the State.

Friedman, M. (1971), proposed the idea that the economic resources that a company destines to the C.S.R. come from three sources; this makes sense and seems to be quite valid: the first resource is the money obtained from entrepreneurs or investors; the second resource are the workers and the third resource are the consumers.

The first idea is very simple to explain, it is an economic donation that the entrepreneur offers to a social benefit cause.

The second idea would be related to the working conditions such as: salary, security conditions, environmental conditions, benefits or even salary cuts to cover some social cause.

The third idea goes directly to the price, as the companies are promoted as socially responsible they tend to raise the cost of their product or service; the consumer feels empathetic with the company and accepts this raised price to contribute to the general social welfare.

Certainly it is possible to discuss whether it is a reality that the enterprise should contribute to social welfare or just to produce wealth; but what should be clear is that the social responsibility of the company must start in an internal and direct way towards its own employees.

\section{Business Management Perspective}

From the perspective of the business management, the C.S.R. is developed in a more holistic way, it is assumed from the ethical, social and philanthropic aspect, but also as a valid tool to the investment return or as a business opportunity.

In that holistic way it is also considered the implementation of strategic projects that have a direct impact to solve some social problems, but that is not the final goal, because the original purpose is the generation of a positive dynamic for the parties. In this way Vives (2004) mentions that the corporative practices, as a part of the corporative strategy, in addition and support of the most important business activities, seeks to avoid the harm and to promote the well-being of the stakeholders (employees, financial sources, community, 
government and environment) to fulfill the rules and the regulations and even going voluntarily beyond these.

If so, one of the main stakeholders as mentioned by Vives, is the employee and without any doubt a good improvement working conditions project meets the conditions mentioned in the corporate strategy of C.S.R. because this promotes the well-being in the environment of the employee, also improving the company infrastructure and finding a niche of investment return. On one hand, with the increase of the workforce productivity, on the other hand, with the savings derived from the quality processes improvements, the reduction of waste and the manufacturing process defects.

Bull, B (2004) says that the behavior of C.S.R. depends on two aspects: a) The one that is related to the economic sector and the specific industry, and b) The one that comes from the relations between the State and the companies. But he also proposes the inclusion of Political Economy to analyze that some companies take into consideration C.S.R. more than others. Given this explanation; we will proceed to present the case study: this case agrees with the state-company relationship mentioned by Bull, as the S.T.P.S., which is in charge of the P.A.S.S.T. program, invited and encouraged the Mexican companies to adhere to these self-management guidelines of occupational health and safety; in order to prevent diseases, risks and accidents in their workforce.

\section{Public-Private Alliances}

P.P.A. public-private alliances appear as a further proposal to decrease and solve typical social problems of developing economies. In general, Palacios, J. (2008) cites Vaillancourt, (2000) mentioning that P.P.A. are tools used to privatize the tasks and the functions of the government. There are cases of P.P.A. in form of either policies or programs that have the goal of improving in topics as: disease control, investment, economic development, technology exchange and others.

One of these programs is implemented by the STPS that promotes the improvement of infrastructure and working practices. This relationship is firstly formalized by the signature of the company agreement and the STPS. Stiglitz, (1998) mentions that the strategies development, in a proactive approach to transformation, arise firstly from a diagnosis and evaluation of the key opportunities to improve the position of the country in the global market in the medium and long-term, and identifying the primary constraints to be overcome, reduced or eliminated in order to take advantage of those opportunities.

Thus, it becomes necessary to plan and to structure the set of alliances and efforts that, in a pertinent way, identify the niches of opportunity that eventually will produce the country growth. It is also important to observe the 
context of the country as well as the real situation of the public and private sectors, in order to take the joint decisions, to create the strategies that involves the parties; and finally to define the targets oriented to the vulnerable sectors or to the social problems that the program should palliate.

\section{S.T.P.S. - Private Sector Alliance, Description of the P.A.S.S.T.}

The companies that participate in the Occupational Safety and Health Self-Management Program (P.A.S.S.T.), promoted by the Ministry of Labor and Social Security, have this central purpose: to incorporate systematic and preventive actions to ensure working centers avoiding labor accidents and occupational diseases. This volume of successful cases is the first one of a series directed by the Secretariat to record specifically those companies that, based on voluntary commitments of employers and workers, proved some progress in achieving their purpose.

The P.A.S.S.T. is a promotional action of the S.T.P.S.S that favors the self-management in the working area of occupational health and safety, implemented by the Mexican companies' personnel; this actions also aims to promote that the companies establish and operate, in a voluntary way, the Systems of Administration in Occupational Safety and Health, based on national and international standards, and on the applicable regulations. This program finally seeks for committed companies willing to increase their productivity by the promotion of the safe and hygienic working place operation.

P.A.S.S.T. program has established particular objectives: a) To promote schemes of voluntary fulfillment of the labor safety and health norms, with the participation of employers and workers, b) To promote a continuous improvement of prevention of labor accidents and diseases, applying the selfmanagement regulations, c) To reduce labor accidents and diseases; and d) To strengthen the leadership of employers and workers organizations with their representatives in promoting the Self-Management Program in Occupational Safety and Health.

In addition to the general and specific objectives, the P.A.S.S.T. has designed specific guidelines for its operation.

\section{P.A.S.S.T. Guidelines}

The General Guidelines of the Operation Self-Management Program for Safety and Health at Work, has three basic guidelines that will also evaluate its implementation:

- Advisory Guide for the of Occupational Health and Safety Management Systems,

- Guide for the Evaluation of the Operation of Occupational Health and Safety Management Systems, and 


\section{Regulations}

- Guide for the Evaluation of Compliance of Safety and Health at Work

The Advisory Guide for the Installation of Occupational Health and Safety Management Systems aims to provide the working centers a scheme that considers the essential elements of these systems implementation and to monitor the application progress.

The Guide for the Evaluation of the Operation of Occupational Health and Safety Management Systems provides the acceptance and evaluation criteria to assess the operation of these systems, as well as some preventive and corrective actions to be implemented in the working centers.

Finally, the Guide for the Evaluation of Compliance of Safety and Health at Work is a tool that allows a comprehensive review of several provisions applicable to the workplace, with the consequent preventive and corrective measures to be implemented.

\section{Methodology}

Yin (1989) considers that the case study method is appropriated for subjects considered new in practical terms, as, in his opinion, empirical research has the following distinctive characteristics:

- It examines or inquires about a contemporary phenomenon in its real environment

- The boundaries of the phenomenon and its context are not evident

- Multiple data sources are used, and

- A single case can be studied as well as multiple cases.

Carrying out a case study aims to observe and to analyze the studied phenomenon from various points of views, it is possible to collect data and information from various sources and even to analyze it in a quantitative and also in a qualitative way. Initially, it can be said that the nature of the case study methodology is more qualitative, so frequently it is not possible that the results will be equally valid to other cases even with similar conditions.

This study intends to use the methodology of case study, as the object of the study is a group of Mexican companies that voluntarily implemented a program to improve the conditions of safety and occupational health, but collaterally considers the importance of C. S. R. Yin (1989) says that a case study is "an empirical research that investigates a contemporary phenomenon in its real context, where the boundaries between phenomenon and context are not precisely shown, and where multiple sources of evidence are used".

Yin (1989) proposes a "case study protocol", a guide to ensure the reliability and validity of the research, that protocol is created in the obtaining evidence phase and its structure is as follows:

- Case study overview

- Case study questions 
- Procedures to be carried out

- Case study report guide

The guide helps to design the research from a specific starting point, as the phenomena can be so different, each has its own vicissitudes and characteristics.

\section{Successful Case Study Analysis}

Below there is a list of the companies that successfully completed the program; it consists on a description of the state in which the company was before the signature of the agreement and the benefits obtained after the establishment of the guidelines and the program recommendations.

Table 1 shows the twenty-five companies that compose the first group of success stories corresponding to the year 2004. Information such as: company name, state of the Mexican republic where is located, number of workers, number of working accidents before and after the program implementation, the percentage of regulations before and after the program implementation, the decrease in payment of working risk quotas to the Mexican Social Security Institute and the origin of the company's capital.

It is important to highlight some results: firstly, the decrease of working accidents, because from a rate of 2.0756 ( 220 events) decreased to a rate of 0.2736 ( 29 events), that indicates that at least 191 people did not get injured thanks to the application of the P.A.S.S.T. Second point is that the working safety and the care-health laws respect grew on average from $80.82 \%$ to $99.56 \%$ which means a strengthening of the company legal framework. And third, $72 \%$ of the companies achieved significant savings by reducing their share of working risks, which translates into a higher productivity.

These results are enough evidence to ensure accordance to three elements of the C.S.R: the social benefit is observed by improving the quality of the worker life and by keeping them safer. Secondly, the legal aspect, because the company was concerned to cover the applicable working health regulations. And third, the monetary saving as its working risk share diminished thanks to the effective intervention of the P.A.S.S.T.

Figure 1. contains the geographical distribution of the companies that signed the S.T.P.S. agreement. It is observed that the concentration in the zones of the City of Mexico and the State of Mexico, with a total of 8 companies. The north of the republic is represented by Chihuahua, Coahuila, Sonora and San Luis Potosi with 7 companies. The center region formed by Guanajuato, Jalisco and Queretaro have a participation of 4 companies and the left companies are distributed in the rest of Mexico. It is clear that the industrial zone of Mexico is traditionally located in the State of Mexico and the Mexico City, but also that the northern region has more business presence 
due to its proximity to the most important commercial partner of our country: the United States of America.

It might be set that foreign capital firms, especially in developed countries, are more familiar with C.S.R. In Figure 2, the origin of capital is detailed; the United States of America is the foreign country that contributes the most of this sample with six out of thirteen cases.

The empirical evidence confirms that the relationship between the origin of the capital and the C.S.R. culture exists, as the companies that had the highest levels of compliance in the working safety and health before the signature of the legal commitment were precisely foreign companies. Six companies reached levels from 90 to $99.55 \%$ : in this group four are foreign companies, one is a Mexican one and there is not indicated information of the left-one. It is also important to mention that of this group, five reached a score of $100 \%$ after the implementation of the P.A.S.S.T. The effort of the rest of the companies is recognizable, because in spite of having lower levels in the norms of working security and health, were able to manage and to compensate that disadvantage and at the end the majority of them are near to the $100 \%$ of fulfillment.

\section{Qualitative Analysis}

It is important for every analysis of success stories to contrast both, qualitative and quantitative information to make a more accurate construction of the reality. Table 2, contains a series of accounts of the main benefits obtained from the correct installation of the P.A.S.S.T.

Benefits such as the followings: increase of the productivity, waste reduction, best position of the company, improvements of the stakeholders relationships, optimization of energy and environment improvements, among others.

Quantitative data are necessary to measure and to interpret nominally or in percentages the variations that occurred after and before the program implementation. Some data are very interesting and important to consider successful the State -Private initiative link. The reduction of the labor accidents is one of them, as we are talking about the physical, mental and emotional integrity of the human being within his working cycle. However, it is also important to highlight the experience of each company, as the sample is widely varied, even two companies of the same industrial sector has its own particular incidents.

The twenty-five companies contained in this first volume, all successful cases, mention the danger associated with the processes for the worker. In this article is presented only some of them as a reference of the situations that the human beings face in their working area. Some of the hazards related to the process are: eye burns due to a lack of protective 
equipment, lack of machinery protection, lack of an ordered and clean working area and improper handling of hazardous waste.

- The main hazards related to the process are: slips and falls, electric shock, exposure to extreme temperatures, noise and repetitive movements.

- The main hazards related to the main process are: exposure to extreme temperatures, noise, dust, vapors, chemical and biological agents, as well as contact with hazardous chemicals.

- The main risk is: physical, hurt of arms or face by bruises, lacerations or foreign particles in the eyes.

- The main hazards are derived from the possible leakage of dimethyl amine during the process of discharge and/or feeding stage, which would cause a toxic cloud affecting an area of 289.4 meters of radius.

The above examples were taken randomly, with the only purpose of showing the importance of the P.A.S.S.T implementation. As it was possible to reduce the accident rate; organs, limbs and even human lives were saved thanks to this intervention and the new culture of prevention.

\section{Conclusion}

From the perspective of business management and given the analysis of the empirical evidence presented, it is possible to affirm that C.S.R. projects, well planned and structured in a multidimensional way, have positive results both for the vulnerable group or social cause and also for the company: finding a bi-directional benefit relation that can extend to more stakeholders. By providing tangible values to the company such as: economic savings, productivity increasing and infrastructure improvements; but also some intangibles benefits such as: better corporate image position, identity, working climate improvements and the public recognition.

The company has an increasingly imperative role in the social and economic development of the countries; this exponential growth of the private initiative compels the responsibility to permeate the obtained benefits towards some vulnerable sectors. The engine cannot be other than business ethics, then it is possible to start a social welfare project with an internal scope that emanates to the society, such is the case of the program presented in this study.

Public-private alliances represent a concrete factor that can favor the sustainable development, the institutions strengthening and the wealth increase. The Company - State relationship aims to strengthen C.S.R., enhancing the human rights such as: the right to a decent job and a sufficient salary, the right to physical and emotional health, the right to enjoy a good environment, as well as the obligation to maintain it for the next generations. Likewise, this alliance must monitor the responsible and efficient resources use and the energy to not jeopardize the sustainability. 
Improving the working safety and health as well as labor conditions and environment is a social responsibility initiative designed firstly to reduce the number of accidents and workers diseases but it also proved to be a practice that increased the productivity of the workforce, decreased the energy consumption and reduced waste and defects in products. In this way, the logic of what is stated in the initial questioning of this work is fulfilled, if companies and public institutions work together to create and to grant improvements in the working conditions and environment, this will permeate the benefits towards the employee, its family, the core of society; it is possible to said that this is Corporate Social Responsibility.

\section{References:}

1. Bull, B. "Corporate social responsibility: a solution for development in Latin America.". Venezuelan Review of Management, Vol. 9 No. 28 (2004), pp. 1-24.

2. Friedman, M. "The Social Responsibility of the Private Company." Center for Economic and Social Studies, CEES, No. 239 (1971).

3. Mexican Center for Philanthropy, "The concept of corporate social responsibility." [Online]. Available: http://www.cemefi.org/esr/images/stories/pdf/esr/concepto_esr.pdf Accessed on: Oct.16, 2015.

4. Ministry of Economy, "Social responsibility guide." Mexico City. [Online]. Available: http://www.economia.gob.mx/comunidadnegocios/competitividad-normatividad/normalizacion/normalizacioninternacional/iso-26000/guia-de-responsabilidad-social Accessed on: Oct.15, 2015

5. Ministry of Labor and Social Welfare, "Cases of success." Vol. 11 st. Ed Self-management Program in Occupational Safety and Health, Ministry of Labor and Social Welfare Mexico, 2004.

6. Ministry of Labor and Social Welfare, "General Operating Guidelines, P.A.S.S.T." Mexico City: 2008. [Online]. Available: http: //autogestion.S.T.P.S.gob.mx: 8162 / pdf / Guidelines\% 20Generales\% 202008.pdf Accessed on: Nov 3, 2015.

7. Palacios, J. "Public-private alliances and industrial escalation. The case of the high-tech complex of Jalisco, Mexico." Studies and Perspectives, ECLAC 2008.

8. Rochlin, S. "Bringing Corporate Responsibility to Your Company's DNA."

9. Harvard Review, Vol. 83 No. 8 (2005), pp. 31-38.

10. Sen, A. "Development as freedom." Ecological Gazette, Ministry of the Environment and Natural Resources No. 55 (2000), pp. 14-20. 
11. Stitglitz, J. "Towards a new paradigm for development: strategies, policies and processes." Prebisch Lectures at UNCTAD, Geneva, 1998.

12. Vargas Pizarro, M. "Corporate Social Responsibility: in Latin America."

13. Ibero-American Space of Human Rights, pp. 2-18, 2009.

14. Vives, A. "The Role of Multilateral Development Institutions in Fostering Corporate Social Responsibility, Sustainable Development Department."

15. Technical Papers Series, Inter-American Development Bank Washington, D.C., 2004.

16. Yin, R. "Case Study Research. Design and Methods." Applied Social Research Methods Series, Sage Publications, London, 1989.

TABLE I.

DATA OF THE SUCCESSFUL FIRMS, TOME 1.

\begin{tabular}{|c|c|c|c|c|c|c|c|c|c|c|}
\hline Firm & State & $\begin{array}{l}\text { Number } \\
\text { of } \\
\text { workers }\end{array}$ & $\begin{array}{c}\text { Initial } \\
\text { work } \\
\text { accidents } \\
\end{array}$ & $\begin{array}{c}\text { Initial } \\
\text { accident } \\
\text { rate } \\
\end{array}$ & $\begin{array}{c}\text { Final } \\
\text { work } \\
\text { accidents } \\
\end{array}$ & $\begin{array}{c}\text { Final } \\
\text { accident } \\
\text { rate }\end{array}$ & $\begin{array}{c}\text { Initial } \\
\text { fulfillment } \\
\text { percentage }\end{array}$ & $\begin{array}{c}\text { Final } \\
\text { fulfillment } \\
\text { percentage }\end{array}$ & $\begin{array}{c}\text { Decrease } \\
\text { of IMSS } \\
\text { quota } \\
\end{array}$ & Capital \\
\hline 1 & Coahuila & 548 & & 0.0000 & 1 & 0.1825 & & 100 & 1 & EU \\
\hline 2 & Chihuahua & 130 & 6 & 4.6154 & 1 & 0.7692 & 73.6 & 100 & 1 & Ext \\
\hline 3 & Chihuahua & 900 & 9 & 1.0000 & 1 & 0.1111 & 50 & 100 & & UK \\
\hline 4 & Coahuila & 270 & 8 & 2.9630 & 0 & 0.0000 & & 100 & & Mex/Hol \\
\hline 5 & Mexico City & 2500 & 25 & 1.0000 & 5 & 0.2000 & 75 & 100 & & Mex \\
\hline 6 & Mexico City & 350 & & 0.0000 & 1 & 0.2857 & & 96 & 1 & Mex \\
\hline 7 & Mexico City & 310 & 0 & 0.0000 & 0 & 0.0000 & 90 & 100 & & Mex \\
\hline 8 & Edo. de Mex. & 104 & 1 & 0.9615 & 0 & 0.0000 & 98.55 & 100 & & EU \\
\hline 9 & Edo. de Mex. & 97 & 1 & 1.0309 & 0 & 0.0000 & 99 & 100 & 1 & Mex \\
\hline 10 & Edo. de Mex. & 798 & 16 & 2.0050 & 0 & 0.0000 & 89 & 98.96 & & Mex \\
\hline 11 & Edo. de Mex. & 80 & 2 & 2.5000 & 0 & 0.0000 & 85.29 & 99 & & Mex \\
\hline 12 & Edo. de Mex. & 111 & 7 & 6.3063 & 0 & 0.0000 & 70 & 100 & & Mex \\
\hline 13 & Guanajuato & 354 & 36 & 10.1695 & 5 & 1.4124 & & 100 & 1 & Mex \\
\hline 14 & Guanajuato & 159 & 6 & 3.7736 & 1 & 0.6289 & 87 & 97.5 & 1 & EU \\
\hline 15 & Jalisco & 315 & 23 & 7.3016 & 0 & 0.0000 & 73 & 100 & 1 & Mex \\
\hline 16 & Michoacan & 102 & 4 & 3.9216 & 0 & 0.0000 & & 100 & 1 & \\
\hline 17 & Michoacan & 263 & 0 & 0.0000 & 0 & 0.0000 & 92.58 & 100 & 1 & Ext \\
\hline 18 & Morelos & 360 & 2 & 0.5556 & 1 & 0.2778 & 96.3 & 100 & 1 & \\
\hline 19 & Queretaro & 241 & 0 & 0.0000 & 0 & 0.0000 & & 100 & & UK \\
\hline 20 & San Luis Potosi & 70 & 7 & 10.0000 & 1 & 1.4286 & 25 & 100 & 1 & \\
\hline 21 & Sonora & 1075 & 3 & 0.2791 & 0 & 0.0000 & & & 1 & EU \\
\hline 22 & Sonora & 200 & 1 & 0.5000 & 0 & 0.0000 & 80 & 99.5 & 1 & EU \\
\hline 23 & Veracruz & 150 & 7 & 4.6667 & 1 & 0.6667 & 99.55 & 100 & 1 & Ext \\
\hline \multirow[t]{2}{*}{24} & Veracruz & 12 & 0 & 0.0000 & 0 & 0.0000 & & & & EU \\
\hline & & 1100 & 56 & 5.0909 & 11 & 1.0000 & 90.19 & 99.1 & 1 & Jap \\
\hline Total & & 10599 & 220 & 2.0757 & 29 & 0.2736 & 80.8271 & 99.5678 & 15 & \\
\hline
\end{tabular}

Source: Authors' elaboration 


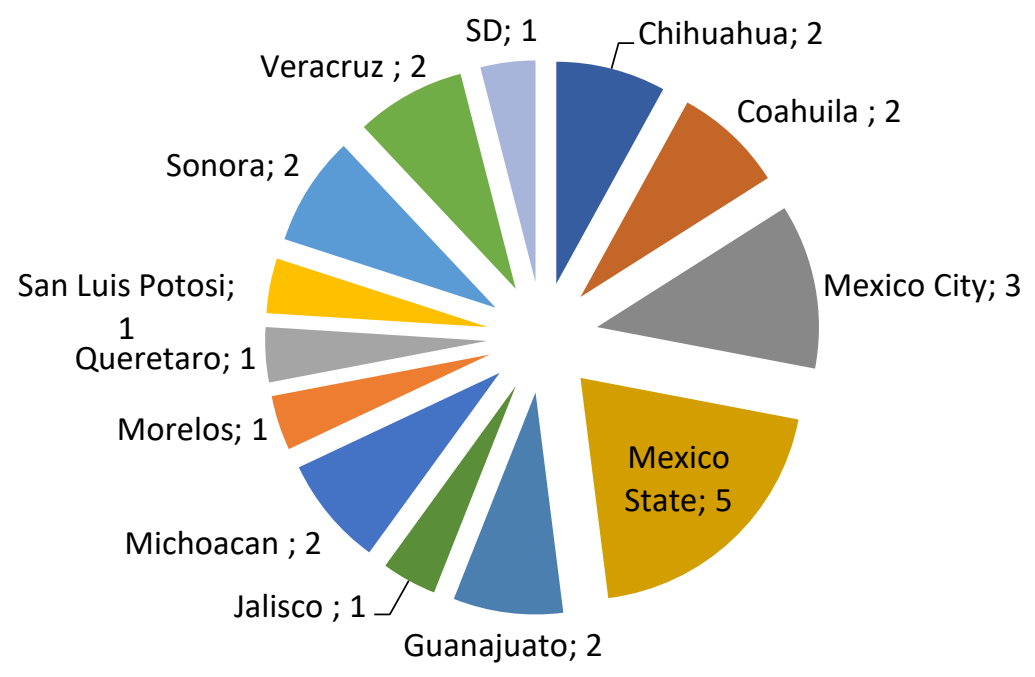

Fig. 1. Geographical location of enterprises, by state.

Source: Authors' elaboration

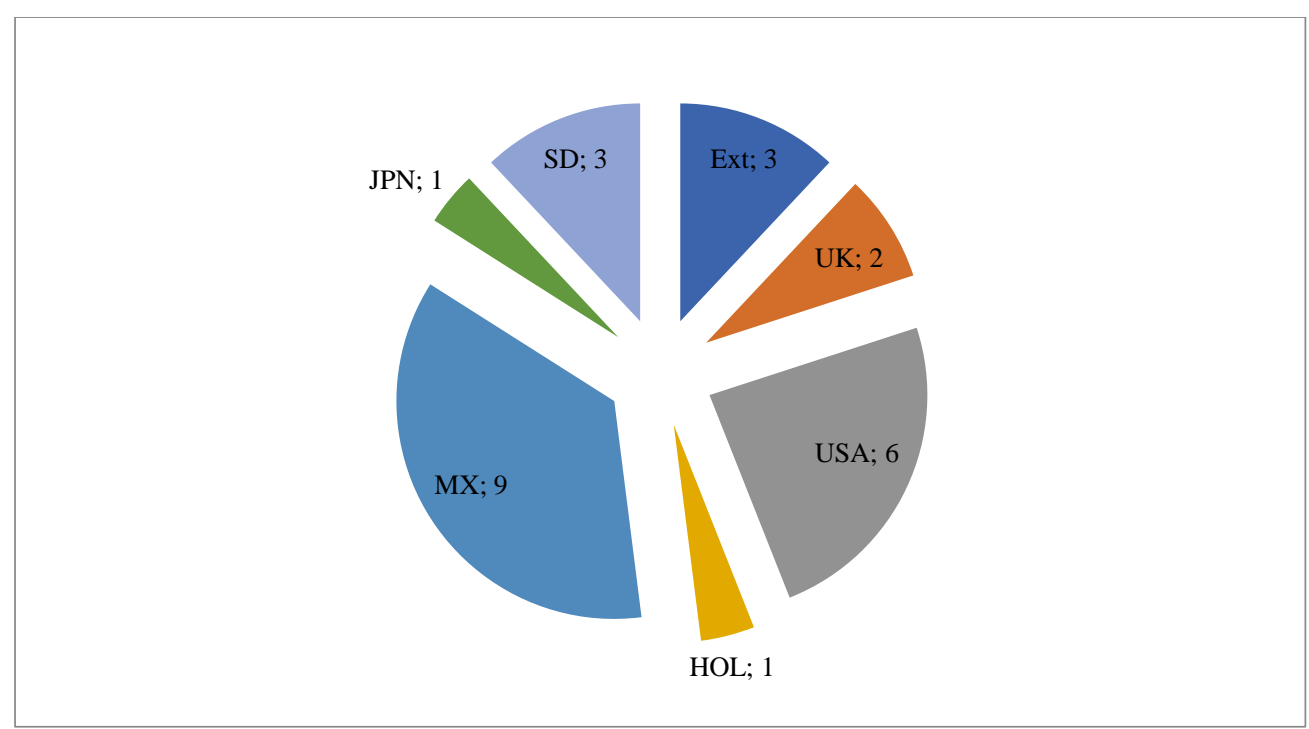

Fig. 2. Enterprises, by origin of capital.

Source: Authors' elaboration 
TABLE II

Description of benefits obtained by the firms

\begin{tabular}{|c|c|}
\hline Firm & Benefits \\
\hline $\mathrm{X} 1$ & Two water treatment plants were built \\
\hline $\mathrm{X} 2$ & The company has obtained new business projects \\
\hline $\mathrm{X} 3$ & The recognition and prestige of the corporate and clients was achieved. \\
\hline $\mathrm{X} 4$ & Evaluation programs were incorporated for contractors and suppliers \\
\hline $\mathrm{X} 5$ & $\begin{array}{c}\text { National Safety Award in the years } 2000 \text { and } 2001 \text { by the Mexican } \\
\text { Association of Hygiene and Safety, A.C }\end{array}$ \\
\hline X6 & $\begin{array}{l}\text { Increased productivity; safer working conditions and greater confidence of the } \\
\text { clients }\end{array}$ \\
\hline $\mathrm{X} 7$ & $\begin{array}{c}\text { The increase in productivity of } 15 \% \text {; reduction of } 5.0 \% \text { in energy consumption } \\
\text { expressed in btu / lb of product; decrease of } 3.0 \% \text { in water consumption; as } \\
\text { well as } 13.9 \% \text { in hazardous waste generation }\end{array}$ \\
\hline $\mathrm{X} 8$ & $\begin{array}{l}\text { Meet the safety requirements of new customers such as Ford, the main } \\
\text { customer. }\end{array}$ \\
\hline $\mathrm{X} 9$ & Recognition of the community, transporters and customers \\
\hline $\mathrm{X} 10$ & $\begin{array}{l}\text { The Environmental, Safety and Health Administration System (SAMASS) was } \\
\text { developed under the ISO } 14001 \text { environment standard, achieving certification } \\
\text { in this standard. }\end{array}$ \\
\hline $\mathrm{X} 11$ & $\begin{array}{l}\text { Economic savings, acceptance and opening of markets, pride of belonging to a } \\
\text { safe company. }\end{array}$ \\
\hline $\mathrm{X} 12$ & $\begin{array}{l}\text { Safety philosophy in family development, by training children of first aid } \\
\text { workers, fire mitigation and accident prevention }\end{array}$ \\
\hline $\mathrm{X} 13$ & $\begin{array}{c}\text { Commitment of employees to the company and its satisfaction, an increase in } \\
\text { productivity and economic savings }\end{array}$ \\
\hline $\mathrm{X} 14$ & $\begin{array}{l}\text { An economic benefit for the company with the decrease of the risk premium of } \\
\text { the IMSS. }\end{array}$ \\
\hline $\mathrm{X} 15$ & $\begin{array}{l}\text { Obtain of the third stage certification by the S.T.P.S., as well as the decrease } \\
\text { of work accidents }\end{array}$ \\
\hline $\mathrm{X} 16$ & $\begin{array}{c}\text { Reduction of operating costs, development of a culture towards safety and } \\
\text { improvement in general working conditions }\end{array}$ \\
\hline $\mathrm{X} 17$ & $\begin{array}{c}10 \% \text { increase in production and efficiency by } 15 \% \text {; costs have remained at } \\
1999 \text { levels; customer's qualification as reliable supplier, enable to gain } \\
\text { contracts and increase of sales }\end{array}$ \\
\hline $\mathrm{X} 18$ & $\begin{array}{l}\text { Creation of the Department of Occupational Health that will benefit } 15 \text { other } \\
\text { hotels of the company, greater added value for the customer }\end{array}$ \\
\hline $\mathrm{X} 19$ & $\begin{array}{l}\text { Problems of production or other economic considerations are not grounds for } \\
\text { reducing the safety of personnel or the environment. }\end{array}$ \\
\hline $\mathrm{X} 20$ & $\begin{array}{c}\text { Continuing production improvement, higher performance of machinery, } \\
\text { increase of new customers }\end{array}$ \\
\hline
\end{tabular}

Source: Authors' elaboration 